\title{
Basolateral Amygdala-Nucleus Accumbens Interactions in Mediating Glucocorticoid Enhancement of Memory Consolidation
}

\author{
Benno Roozendaal, Dominique J.-F. de Quervain, Barbara Ferry, Barry Setlow, and James L. McGaugh \\ Center for the Neurobiology of Learning and Memory and Department of Neurobiology and Behavior, University of \\ California, Irvine, California 92697-3800
}

\begin{abstract}
Systemic or intracerebral administration of glucocorticoids enhances memory consolidation in several tasks. Previously, we reported that these effects depend on an intact basolateral nucleus of the amygdala (BLA) and efferents from the BLA that run through the stria terminalis (ST). The BLA projects directly to the nucleus accumbens (NAc) via this ST pathway. The NAc also receives direct projections from the hippocampus and, therefore, may be a site of convergence of BLA and hippocampal influences in modulating memory consolidation. In support of this view, we found previously that lesions of either the NAC or the ST also block the memory-modulatory effect of systemically administered glucocorticoids. The present experiments examined the effects of lesions of the NAc or the ST on the memory-modulatory effects of intracerebral glucocorticoids on inhibitory avoidance training. Microinfusions of the specific
\end{abstract}

glucocorticoid receptor agonist $11 \beta, 17 \beta$-dihydroxy-6,21dimethyl-17 $\alpha$-pregna-4,6-trien-20yn-3-one (RU 28362; 1.0 or $3.0 \mathrm{ng}$ ) into either the BLA or the hippocampus of male Sprague Dawley rats administered immediately after training enhanced the $48 \mathrm{hr}$ retention performance in a dose-dependent manner. Bilateral lesions of the NAc or the ST alone did not affect retention performance but blocked the memory enhancement induced by intra-BLA or intrahippocampal glucocorticoid receptor agonist administration. These findings indicate that the BLA-NAc pathway plays an essential role in mediating glucocorticoid effects on memory consolidation and suggest that the BLA interacts with hippocampal effects on memory consolidation via this pathway.

Key words: hippocampus; inhibitory avoidance; memory storage; stria terminalis; $R U$ 28362; ventral striatum
It is well established that adrenocortical hormones are involved in mediating stress effects on cognitive performance (Lupien and McEwen, 1997; de Kloet et al., 1999; Roozendaal, 2000). Evidence that systemic injections of corticosterone or glucocorticoid receptor (GR or type II) agonist, administered to rats or mice immediately after training, enhance retention indicates that glucocorticoids strengthen memory consolidation (Kovacs et al., 1977; Flood et al., 1978; Roozendaal and McGaugh, 1996a). The hippocampal formation, which expresses high densities of adrenal steroid receptors (Reul and de Kloet, 1985), is considered a major target for glucocorticoids in influencing memory consolidation (Micheau et al., 1985; Roozendaal and McGaugh, 1997a). Recent findings indicate that the amygdala, which has a moderate density of GRs (Honkaniemi et al., 1992), also participates in the influence of glucocorticoids on memory consolidation (Roozendaal, 2000). Post-training infusions of a GR agonist into the basolateral nucleus of the amygdala (BLA), but not the immediately adjacent central nucleus of the amygdala (CEA), enhance memory (Roozendaal and McGaugh, 1997b). Selective lesions of the BLA, but not the CEA, block the memory-enhancing effects of systemic glucocorticoid administration (Roozendaal and McGaugh, 1996a). Moreover, lesions or functional disruption of the

Received Oct. 25, 2000; revised Dec. 11, 2000; accepted Jan. 10, 2001.

This research was supported by a Ralph W. and Leona Gerard Family Trust Fellowship to B.R. and B.F. and by United States Public Health Service National Institute of Mental Health Research Grant MH 12526 to J.L.M. We thank Jason Buranday, Jamin Pablo, and Bichngoc Nguyen for excellent technical assistance and Dr. Rafael Roesler for comments on a previous draft of this manuscript. RU 28362 was generously provided by Roussel UCLAF (Romainville, France).

Correspondence should be addressed to Dr. Benno Roozendaal, Center for the Neurobiology of Learning and Memory, University of California, Irvine, CA 926973800. E-mail: broozend@uci.edu.

Copyright @ $\odot 2001$ Society for Neuroscience $0270-6474 / 01 / 212518-08 \$ 15.00 / 0$
BLA blocks modulation of memory consolidation initiated by treatments affecting hippocampal GRs (Roozendaal and McGaugh, 1997a; Roozendaal et al., 1999).

These findings strongly support the view that the BLA mediates arousal and stress hormone effects on memory consolidation processes elsewhere in the brain (McGaugh et al., 1996; Cahill and McGaugh, 1998; McGaugh, 2000; Roozendaal, 2000). The BLA projects directly to the entorhinal cortex and the hippocampus (Thomas et al., 1984; Pikkarainen et al., 1999). Administration of NMDA into the amygdala induces c-fos expression in the ipsilateral dentate gyrus (Packard et al., 1995), and BLA electrical stimulation enhances the induction of population spike longterm potentiation (LTP) in the dentate gyrus in vivo (Ikegaya et al., 1995; Akirav and Richter-Levin, 1999). Furthermore, BLA lesions attenuate the induction of perforant path LTP (Ikegaya et al., 1994) and block stress-induced impairment of hippocampal LTP (Sharp et al., 1999). However, our previous findings suggested an alternative route of BLA-hippocampal interaction. Because lesions of either the nucleus accumbens (NAc) or the stria terminalis (ST), a fiber bundle carrying projections from the BLA to the NAc (Kelley et al., 1982; Wright et al., 1996), block the memory-modulatory effects of systemic glucocorticoids administered after training (Roozendaal and McGaugh, 1996b; Setlow et al., 2000), it might be that information from the BLA and the hippocampus converge in the NAc in modulating memory consolidation.

The present experiments addressed this issue further by examining whether NAc or ST lesions block the enhancing effects of intra-BLA infusions of a GR agonist on memory for inhibitory avoidance training, a task in which both the hippocampus and the NAc are involved (Lorenzini et al., 1995; Taubenfeld et al., 1999). 
Additionally, we examined whether lesions of the NAc or the ST block the memory enhancement induced by post-training GR agonist inf usions into the hippocampus to determine whether the enabling influence of the BLA on hippocampal-dependent memory formation is mediated via this pathway.

\section{MATERIALS AND METHODS}

Subjects. Male Sprague Dawley rats (270-300 gm at time of surgery) from Charles River Laboratories (Wilmington, MA) were used. They were kept individually in a temperature-controlled $\left(22^{\circ} \mathrm{C}\right)$ colony room and maintained on a standard 12/12 hr light/dark cycle (lights on, 0700-1900 $\mathrm{hr}$ ) with ad libitum access to food and water. Training and testing were performed during the light phase of the cycle between 1000 and $1500 \mathrm{hr}$.

Surgery. The animals were adapted to the vivarium for at least 1 week before surgery. They were anesthetized with sodium pentobarbital (50 $\mathrm{mg} / \mathrm{kg}$ of body weight, i.p.) and given atropine sulfate $(0.4 \mathrm{mg} / \mathrm{kg}$, i.p) to maintain respiration. The skull was positioned in a stereotaxic frame (Kopf Instruments, Tujunga, CA), and bilateral lesions of the NAc or the ST were made, followed by bilateral cannulae placement just above the BLA or the dorsal hippocampus. Bilateral lesions of the NAc were made with NMDA (Sigma, St. Louis, MO; $12.5 \mu \mathrm{g}$ per $1.0 \mu \mathrm{l}$ of phosphate buffer, $\mathrm{pH}$ 7.4). The NMDA solution was back-filled into a 30 gauge needle, which was attached by a polyethylene tube to a $10 \mu$ l Hamilton microsyringe, driven by a minipump (Sage Instruments, Boston, MA). The needle was placed into the NAc, and $0.3 \mu \mathrm{l}$ of NMDA solution was infused over $34 \mathrm{sec}$, after which the needle was left in place for 3 additional minutes to allow for diff usion. The following coordinates were based on the atlas of Paxinos and Watson (1997): anteroposterior (AP), $+1.9 \mathrm{~mm}$ from bregma; mediolateral (ML), $\pm 1.6 \mathrm{~mm}$ from midline; and dorsoventral (DV), $-7.4 \mathrm{~mm}$ from the skull surface, with the incisor bar $-3.3 \mathrm{~mm}$ from the interaural line. For sham lesions the tip of the needle was lowered only $5.4 \mathrm{~mm}$ below the skull surface and left in place for 3 min without an infusion. Bilateral lesions of the ST were produced by radio-frequency current (1.5 V; $20 \mathrm{sec}$; Grass Instrument model LM-3) administered through bipolar electrodes (twisted, paired stainless steel wires with tips $0.5 \mathrm{~mm}$ apart; insulated except for $0.5 \mathrm{~mm}$ at the tip) at the following coordinates: AP, $-0.3 \mathrm{~mm}$; ML, $\pm 3.0 \mathrm{~mm}$; and DV, $-5.4 \mathrm{~mm}$, according to the atlas of Pellegrino et al. (1979). Sham lesions followed the same procedure except that the electrode was lowered only $4.0 \mathrm{~mm}$ below the skull surface and no current was passed.

Immediately after lesioning of either the NAc or the ST, the animals were placed in another stereotaxic frame, and two stainless steel guide cannulae (23 gauge) were implanted bilaterally with the cannula tips either $2 \mathrm{~mm}$ above the BLA (15 mm long; coordinates, AP, $-2.8 \mathrm{~mm}$; $\mathrm{ML}, \pm 5.0 \mathrm{~mm}$; and DV,$-6.5 \mathrm{~mm}$ ) or $1.5 \mathrm{~mm}$ above the dorsal hippocampus (11 mm long; coordinates, AP, $-3.3 \mathrm{~mm}$; ML, $\pm 1.5 \mathrm{~mm}$; and DV, $-2.6 \mathrm{~mm}$ ) according to the atlas of Paxinos and Watson (1997). The cannulae were affixed to the skull with two anchoring screws and dental cement. Stylets (11- or 15-mm-long 00 insect dissection pins) were inserted into each cannula to maintain patency and were removed only for the infusion of drugs. After surgery, the rats received a subcutaneous $3.0 \mathrm{ml}$ injection of saline to prevent dehydration and were placed into an incubator until recovery from anesthesia, after which they were returned to their home cages. The rats were allowed to recover a minimum of $7 \mathrm{~d}$ before initiation of training and were handled three times for 1 min each during this recovery period to get accustomed to the infusion procedures.

Inhibitory avoidance apparatus and procedure. The rats were trained and tested in an inhibitory avoidance apparatus consisting of a troughshaped alley $(91 \mathrm{~cm}$ long, $15 \mathrm{~cm}$ deep, $20 \mathrm{~cm}$ wide at the top, and $6.4 \mathrm{~cm}$ wide at the floor) divided into two compartments, separated by a sliding door that opened by retracting into the floor (McGaugh et al., 1988). The starting compartment ( $31 \mathrm{~cm}$ long) was made of opaque white plastic and was well lit; the shock compartment $(60 \mathrm{~cm}$ long) was made of dark, electrifiable metal plates and was not illuminated. Training and testing were conducted in a sound- and light-attenuated room.

The rat was placed in the starting compartment of the apparatus, facing away from the door, and was allowed to enter the dark compartment. After the animal stepped completely into the shock compartment, the door was closed, and a single foot shock was delivered for $1 \mathrm{sec}$. Because previous studies have shown that vehicle infusions into the BLA, but not the hippocampus, induce memory impairment for inhibitory avoidance training (Roozendaal and McGaugh, 1997a,b), animals with BLA cannulae received a higher foot-shock intensity $(0.5 \mathrm{~mA})$ than did animals with cannulae aimed at the dorsal hippocampus $(0.4 \mathrm{~mA})$. Animals showing entrance latencies on the training trial of $>30 \mathrm{sec}$ were eliminated from the study. The animals were removed from the shock compartment $15 \mathrm{sec}$ after termination of the foot shock and, after drug treatment, were returned to their home cages. On the $48 \mathrm{hr}$ retention test, as on the training session, the latency to reenter the shock compartment with all four paws (maximum latency of $600 \mathrm{sec}$ ) was recorded and used as the measure of retention. Longer latencies were interpreted as indicating better retention. Shock was not administered on the retention test trial. Extensive previous evidence indicates that avoidance of the shock area indicates specific memory of the place where shock had been received (Gold, 1986; Vazdarjanova and McGaugh, 1998; Liang, 2001).

Drug and infusion procedures. The specific GR agonist $11 \beta, 17 \beta$ dihydroxy-6,21-dimethyl-17 $\alpha$-pregna-4,6-trien-20yn-3-one (RU 28362; Roussel UCLAF, Romainville, France) was infused into either the BLA (1.0 or $3.0 \mathrm{ng}$ in $0.2 \mu \mathrm{l}$ ) or the dorsal hippocampus (1.0 or $3.0 \mathrm{ng}$ in $0.5 \mu \mathrm{l}$ ) immediately after training. Receptor-binding studies have shown that this compound has a selective and high affinity for GRs (Teutsch et al., 1981). The drug was first dissolved in $100 \%$ ethanol and subsequently diluted with saline to reach its appropriate concentration. The final concentration of ethanol was $2 \%$. The vehicle solution contained $2 \%$ ethanol in saline only. Inf usions of RU 28362 or an equivalent volume of vehicle control into the BLA were made by using a 30 gauge injection needle connected to a $10 \mu \mathrm{l}$ Hamilton microsyringe by polyethylene (PE-20) tubing. For infusions into the BLA, the injection needle protruded $2 \mathrm{~mm}$ beyond the tip of the cannula, and a $0.2 \mu \mathrm{l}$ injection volume was infused over a period of $25 \mathrm{sec}$ by an automated syringe pump (Sage Instruments). The infusion volume was based on findings that this volume of NMDA solution into an identical injection site induces selective neurotoxic lesions of the BLA (Roozendaal and McGaugh, 1996a). Furthermore, drug infusions of this volume into either the BLA or the adjacent CEA induce differential effects on memory consolidation (Parent and McGaugh, 1994; Roozendaal and McGaugh, 1997b). The injection needle was retained within the cannula for an additional $20 \mathrm{sec}$ after drug infusion to maximize diff usion and to prevent backflow of drug into the cannulae. The experimental procedure for intrahippocampal infusions was similar to that described for infusions into the BLA except that a volume of $0.5 \mu \mathrm{l}$ was infused over a $36 \mathrm{sec}$ period and that the injection needle protruded $1.5 \mathrm{~mm}$ beyond the cannula tip. The doses were selected on the basis of previous experiments conducted in this laboratory (Roozendaal and McGaugh, 1997a).

Histology. The rats were anesthetized with an overdose of sodium pentobarbital $(\sim 100 \mathrm{mg} / \mathrm{kg}$, i.p.) and perfused intracardially with $0.9 \%$ saline $(\mathrm{w} / \mathrm{v})$ solution followed by $4 \%$ formaldehyde $(\mathrm{w} / \mathrm{v})$ dissolved in water. After decapitation, the brains were removed and placed in $4 \%$ formaldehyde. At least $24 \mathrm{hr}$ before sectioning, the brains were submerged in a $20 \%$ sucrose (w/v) solution for cryoprotection. Sections of 40 $\mu \mathrm{m}$ were made using a freezing microtome and stained with cresyl violet. The sections were examined under a light microscope, and determination of the size and location of the lesions in either the NAc or ST as well as the location of injection needle tips in the BLA and hippocampus was made according to the standardized atlas plates of Paxinos and Watson (1997) by an observer blind to the drug treatment condition.

Statistics. The retention test latencies of the different experiments were analyzed separately using a two-factor ANOVA with sham and lesioned animals (two levels) and intra-BLA or intrahippocampal infusions of vehicle or different doses of the GR agonist (three levels) as betweensubject variables. Further analysis used Fisher's post hoc tests to determine the sources of significance. A probability level of $<0.05$ was accepted as statistically significant. One outlier (an animal with a retention latency outside of the range of $\pm 2 \mathrm{SD}$ from the group mean) was excluded from the NAc sham group with intra-BLA infusions of RU 28362 (3.0 ng). There were $7-15$ rats per group as indicated in the figure legends.

\section{RESULTS}

\section{Histology}

Cannula placement

Animals with improper cannula placement or with extensive damage to the targeted tissue were excluded from the analyses. Figure $1, A$ and $B$, shows photomicrographs illustrating representative locations of injection needle tips in the BLA and the dorsal hippocampus, respectively. 

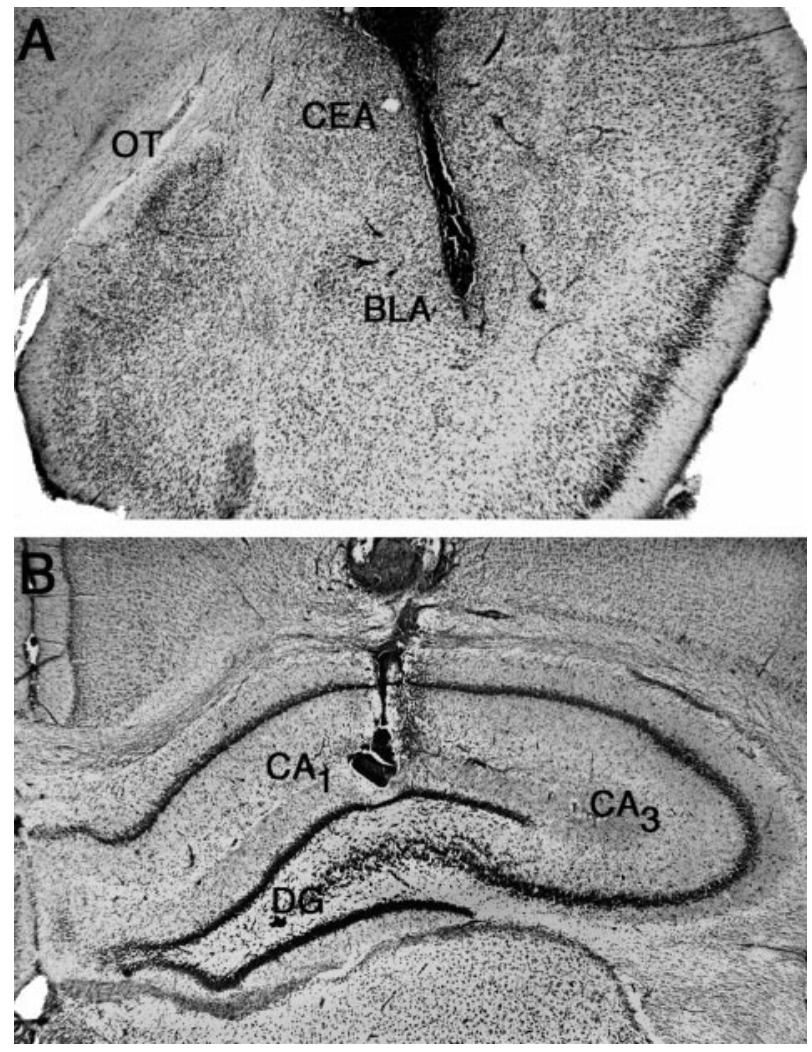

Figure 1. Representative photomicrographs illustrating placement of cannula in the basolateral amygdala $(A)$ or dorsal hippocampus $(B) . B L A$, Basolateral nucleus of the amygdala; $C A 1, C A 3$, Ammon's horn; $C E A$, central nucleus of the amygdala; $D G$, dentate gyrus; $O T$, optic tract.

\section{NAc lesions}

Animals with misplaced or absent lesions were excluded from further analysis, leaving 51 animals in the NAc-lesioned groups. The largest and smallest lesions are shown in Figure $2 A$, and a representative lesion and a sham control are shown in Figure 2, $B$ and $C$, respectively. The lesions were primarily confined to the NAc core and anterior NAc shell. However, some of the larger lesions spread along the anterior limb of the anterior commissure and damaged the posterior medial shell as well. There was also occasional damage to the caudate-putamen overlying the NAc. In $\sim 25$ of the animals (49\%), the posterior spread of the lesions along the anterior limb of the anterior commissure caused partial damage to the bed nucleus of the stria terminalis and ventral pallidum. This damage was in all cases unilateral and did not encroach on the lateral hypothalamus or medial septum.

\section{ST lesions}

The maximum and minimum extents of the lesions $(n=66)$ are shown in Figure $3 A$, and a representative lesion and a sham control are shown in Figure $3, B$ and $C$, respectively. In most animals the ST lesions also included the most dorsal aspects of the caudate-putamen and anterior, dorsomedial, and ventrolateral thalamic areas. The most ventrolateral part of the fimbria, immediately adjacent to the ST, showed occasionally minor damage, but in all animals a minimum of $\sim 85-90 \%$ of the fimbria remained intact. The fornix, which carries information from the subiculum to the NAc, was spared in all cases. Animals were included in the analyses only if the ST was damaged entirely at, at least, one rostrocaudal location. Seventy-one animals were ex- cluded from the final analysis because of inappropriate locus and size of the lesions.

\section{Effects of NAc or ST lesions on intra-BLA infusions of RU 28362}

Previous studies from our laboratory have shown that systemic injections of glucocorticoids given immediately after inhibitory avoidance training induce dose-dependent memory enhancement. These effects are blocked by lesions of the NAc or the ST (Roozendaal and McGaugh, 1996b; Setlow et al., 2000), suggesting that these structures are a critical part of a memorymodulatory system. Because infusions of glucocorticoids into the BLA induce similar memory enhancement (Roozendaal and McGaugh, 1997b), the present experiments evaluated whether either NAc or ST lesions block the memory enhancement induced by intra-BLA infusions of glucocorticoids. The first experiment examined the effects of bilateral NAc lesions. Latencies of rats with sham lesions or NAc lesions to enter the shock compartment on the training trial, before foot-shock exposure, did not differ $[$ mean \pm SEM, for sham-lesioned rats, $14.3 \pm 1.0 \mathrm{sec}$; for NAclesioned rats, $14.2 \pm 1.2 \mathrm{sec} ; F_{(1,58)}=0.01$; NS; data not shown]. Figure $4 A$ shows the inhibitory avoidance retention latencies of rats with sham or bilateral NAc lesions given immediate posttraining inf usions of the GR agonist RU 28362 or vehicle into the BLA. Retention latencies of sham-lesioned rats given vehicle infusions were significantly longer than were their entrance latencies during the training trial (paired $t$ test, $p<0.005$ ), indicating memory for the task. A two-factor ANOVA for retention trials revealed no significant lesion $\left[F_{(1,54)}=1.70\right.$; NS $]$ or overall drug effects $\left[F_{(2,54)}=1.91\right.$; NS $]$ but did reveal a significant interaction between these two factors $\left[F_{(2,54)}=3.59 ; p<0.05\right]$. The retention latencies of sham-lesioned rats given vehicle infusions in the BLA were short $(67.6 \pm 12.9 \mathrm{sec})$ as was expected because of the low foot-shock intensity used. Post-training infusions of the lower dose of the GR agonist RU 28362 (1.0 ng) into the BLA of sham-lesioned rats enhanced retention of rats relative to corresponding vehicle-treated rats $(p<0.01)$. The higher dose of RU 28362 (3.0 ng) did not enhance retention. Lesions of the NAc alone did not impair retention latencies but, most important, blocked the retention-enhancing effects of RU 28362 administered into the BLA. Furthermore, retention latencies of RU 28362-treated rats $(1.0 \mathrm{ng})$ with NAc lesions were significantly shorter than were retention latencies of RU 28362-treated rats (1.0 ng) with sham lesions $(p<0.05)$.

We next evaluated whether lesions of the ST would block the memory-enhancing effect of post-training intra-BLA infusions of RU 28362. A one-factor ANOVA revealed no significant difference between rats with sham lesions (mean \pm SEM, $13.9 \pm 1.2$ $\mathrm{sec})$ and ST lesions $(15.3 \pm 1.0 \mathrm{sec})$ in their latencies to enter the shock compartment during training $\left[F_{(1,72)}=0.69 ;\right.$ NS $]$. Figure $4 B$ shows the inhibitory avoidance retention latencies of rats with bilateral ST lesions given GR agonist infusions into the BLA. Retention latencies of sham-lesioned rats given vehicle infusions were significantly longer than were their entrance latencies during the training trial (paired $t$ test, $p<0.05$ ). A two-factor ANOVA for retention latencies revealed no significant lesion $\left[F_{(1,68)}=\right.$ 2.25 ; NS $]$ or drug effects $\left[F_{(2,68)}=1.98 ; \mathrm{NS}\right]$ but did indicate a significant interaction between these two factors $\left[F_{(2,68)}=3.71\right.$; $p<0.05]$. Similarly, as described above, only post-training infusions of the lower $(1.0 \mathrm{ng})$ and not the higher $(3.0 \mathrm{ng})$ dose of the GR agonist RU 28362 into the BLA enhanced retention of sham-lesioned rats relative to vehicle-treated rats $(p<0.01)$. ST 

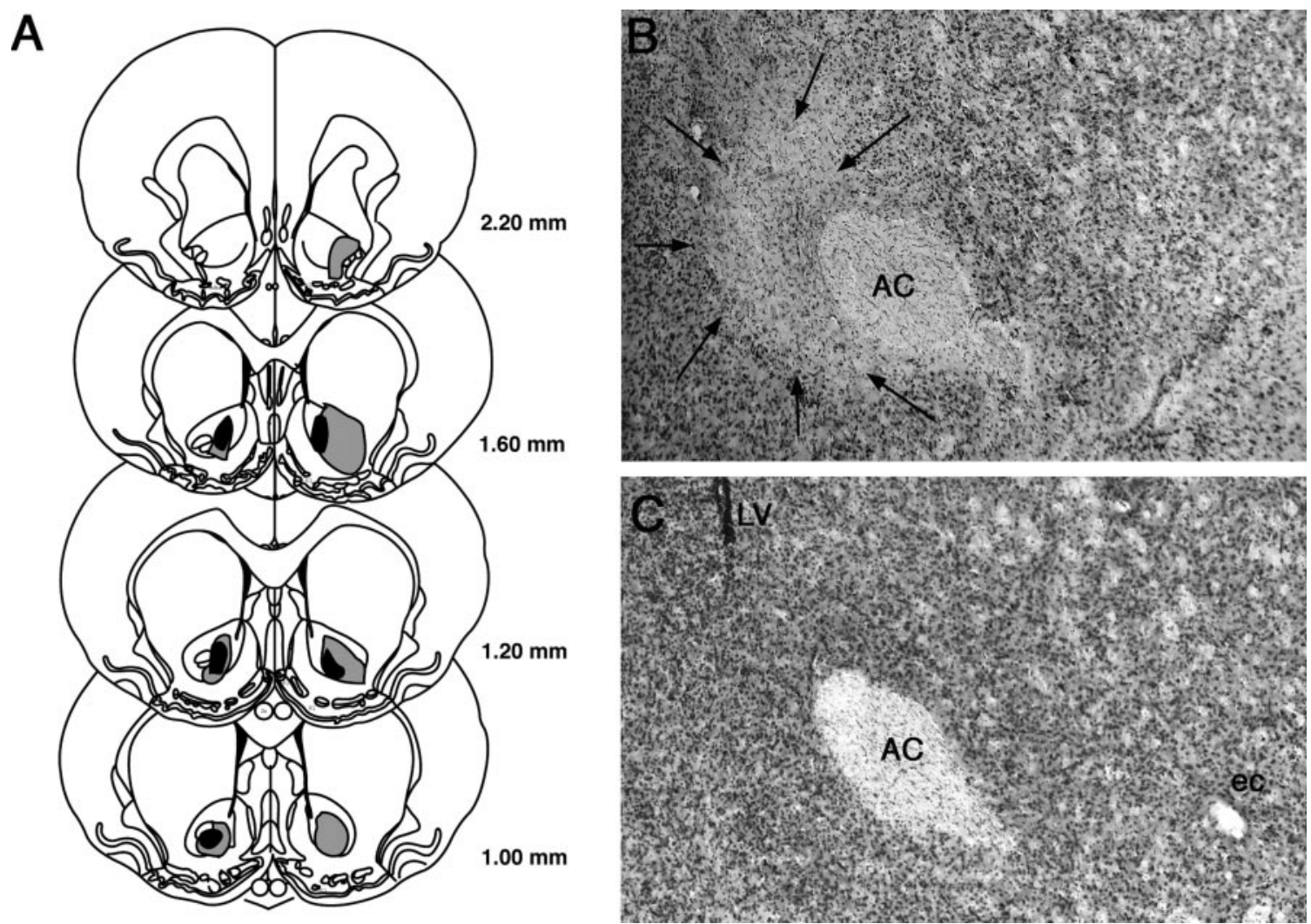

Figure 2. A, Maximum ( gray-shaded area) and minimum (black-shaded area) extents of the nucleus accumbens lesions. Plates are adapted from the atlas of Paxinos and Watson (1997). B, Representative nucleus accumbens lesion. Arrows denote lesion borders. $C$, Sham-lesioned control. AC, Anterior limb of the anterior commissure; $e c$, external capsule; $L V$, lateral ventricle.

lesions alone did not significantly affect retention latencies but blocked the retention-enhancing effect of RU 28362 administered into the BLA $(p<0.05)$.

\section{Effects of NAc or ST lesions on intrahippocampal infusions of RU 28362}

Previously, we reported that post-training infusions of RU 28362 into the hippocampus also enhance inhibitory avoidance retention and that these effects are blocked by lesions of the BLA (Roozendaal and McGaugh, 1997a). The present study examined whether this BLA influence is conveyed via ST efferent projections to the NAc to interact with hippocampal memory consolidation processes. This experiment investigated whether lesions of either the NAc or the ST blocked memory enhancement induced by immediate post-training intrahippocampal infusions of RU 28362. In agreement with the findings of the first experiment, NAc lesions did not affect latencies to enter the shock compartment on the training trial [mean \pm SEM, for sham-lesioned rats, $13.4 \pm 0.9 \mathrm{sec}$; for NAc-lesioned rats, $12.6 \pm 1.3 \mathrm{sec} ; F_{(1,64)}=$ 0.23 ; NS; data not shown]. Inhibitory avoidance retention latencies of rats with bilateral NAc lesions given immediate posttraining inf usions of vehicle or the GR agonist RU 28362 into the dorsal hippocampus are shown in Figure $5 A$. The rats certainly learned the task because retention latencies of sham-lesioned rats given vehicle infusions were significantly longer than were their entrance latencies during the training trial (paired $t$ test, $p<$ 0.01). A two-factor ANOVA for retention latencies revealed no significant lesion $\left[F_{(1,60)}=0.23\right.$; NS] or overall drug effects $\left[F_{(2,60)}=1.91 ; \mathrm{NS}\right]$ but did indicate a significant interaction between these two factors $\left[F_{(2,60)}=3.15 ; p<0.05\right]$. Post-training infusions of the higher dose of RU 28362 (3.0 ng) into the hippocampus enhanced retention of sham-lesioned rats as compared with the corresponding vehicle-treated rats $(p<0.05)$. The lower dose of RU 28362 (1.0 ng) did not enhance retention. NAc lesions alone did not affect retention latencies but blocked the retention-enhancing effects of the higher dose of RU 28362 administered into the hippocampus $(p<0.05)$.

A one-factor ANOVA revealed no significant difference between rats with sham lesions (mean \pm SEM, $10.8 \pm 1.1 \mathrm{sec}$ ) and ST lesions $(13.4 \pm 1.2 \mathrm{sec})$ in their latencies to enter the shock compartment during training $\left[F_{(1,73)}=2.58\right.$; NS]. Inhibitory avoidance retention latencies of rats with bilateral ST lesions given GR agonist infusions into the dorsal hippocampus are shown in Figure 5B. Retention latencies of sham-lesioned rats given vehicle infusions were significantly longer than were their entrance latencies during the training trial (paired $t$ test, $p<$ 0.0005). A two-factor ANOVA for retention latencies revealed no significant lesion $\left[F_{(1,68)}=0.95 ; \mathrm{NS}\right]$ or drug effects $\left[F_{(2,68)}=\right.$ 2.04; NS] but did reveal a significant interaction between these two factors $\left[F_{(2,68)}=3.35 ; p<0.05\right]$. Similarly, as described above, only post-training infusions of the higher dose of the GR agonist RU 28362 (3.0 ng) into the hippocampus enhanced retention of rats relative to vehicle-treated rats $(p<0.05)$. ST lesions alone did not significantly affect retention latencies but blocked the retention-enhancing effects of RU 28362 administered into the hippocampus. Furthermore, retention latencies of RU 28362-treated rats (3.0 ng) with ST lesions were significantly shorter than were retention latencies of RU 28362-treated rats (3.0 ng) with sham lesions $(p<0.05)$. 

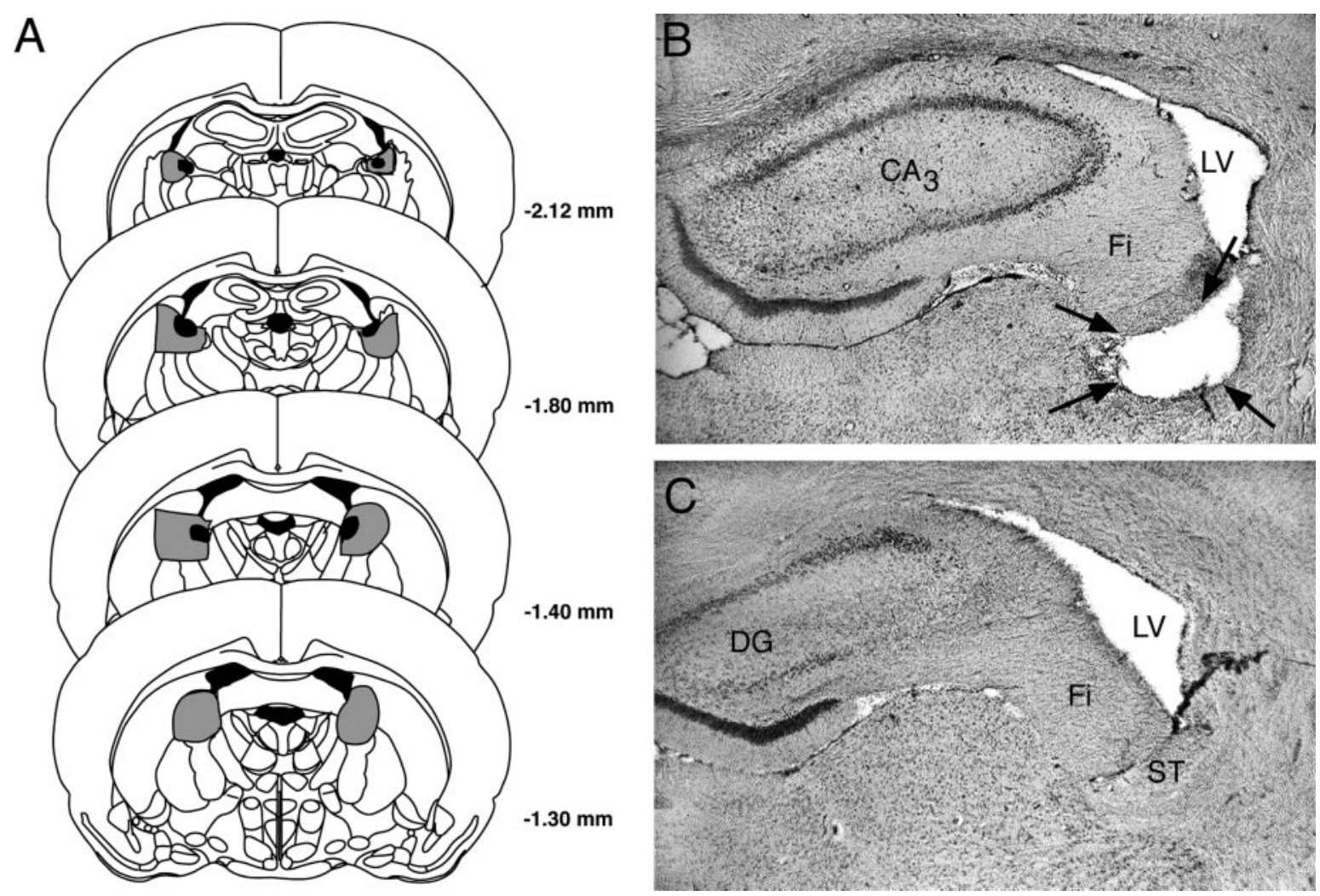

Figure 3. A, Maximum ( gray-shaded area) and minimum (black-shaded area) extents of the stria terminalis lesions. Plates are adapted from the atlas of Paxinos and Watson (1997). B, Representative stria terminalis lesion. Arrows denote lesion borders. $C$, Sham-lesioned control. $C A 3$, Ammon's horn; $D G$, dentate gyrus; $F i$, fimbria; $L V$, lateral ventricle; $S T$, stria terminalis.

Figure 4. Step-through latencies (mean \pm SEM) for the 48 hr retention test of rats with lesions of either the nucleus accumbens $(A)$ or the stria terminalis $(B)$ given microinfusions of vehicle or the specific glucocorticoid receptor agonist RU 28362 (1.0 or $3.0 \mathrm{ng}$ in $0.2 \mu \mathrm{l})$ into the basolateral amygdala immediately after inhibitory avoidance training. $*_{p} p<0.01$ compared with the corresponding vehicle group; $\diamond p<0.05$ compared with the corresponding sham-lesion group ( $n=7-15$ per group). $N$., Nucleus.
BASOLATERAL AMYGDALA INFUSIONS

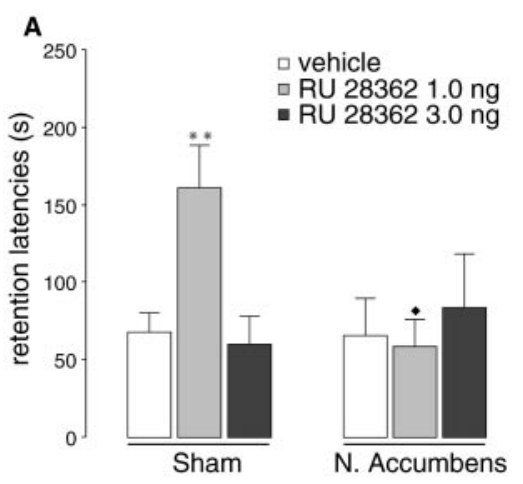

\section{DISCUSSION}

The novel findings of these experiments are that bilateral lesions of either the NAc or the ST block the retention enhancement produced by immediate post-training infusions of a GR agonist into either the BLA or the hippocampus. These findings are consistent with previous evidence indicating that NAc and ST lesions prevent the memory-enhancing effect of systemic glucocorticoid injections on the same task (Roozendaal and McGaugh, 1996b; Setlow et al., 2000) and complement findings that BLA lesions block the memory-enhancing effects of intrahippocampal GR agonist infusions (Roozendaal and McGaugh, 1997a). Sham and lesioned animals did not differ in training or retention latencies in groups given vehicle infusions. Because the lesions alone did not affect retention, the BLA-NAc pathway does not appear to be critical for either the acquisition or expres-

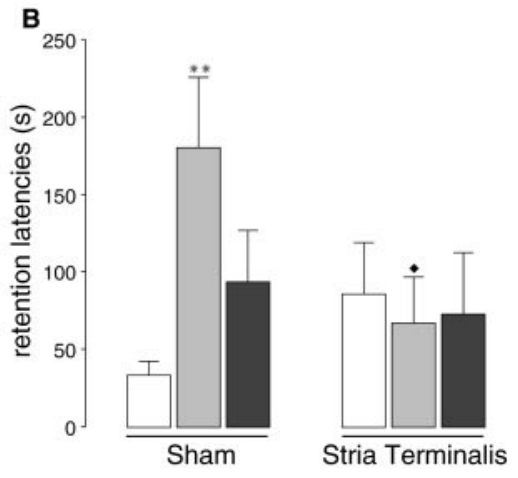

sion of memory for inhibitory avoidance training (Liang et al., 1990; Introini-Collison et al., 1991; Roozendaal and McGaugh, 1996b; Setlow et al., 2000). However, both are certainly involved in influencing memory consolidation, because reversible functional inactivation of either the BLA or the NAc immediately after training impairs later retention (Parent and McGaugh, 1994; Lorenzini et al., 1995).

\section{Glucocorticoid-induced enhancement of memory consolidation}

Our findings that immediate post-training GR agonist infusions administered into either the BLA or the hippocampus enhanced later retention in a dose-dependent manner are consistent with those of previous studies (Roozendaal and McGaugh, 1997a,b; Roozendaal et al., 1999). Hippocampal infusions required a 
HIPPOCAMPUS INFUSIONS

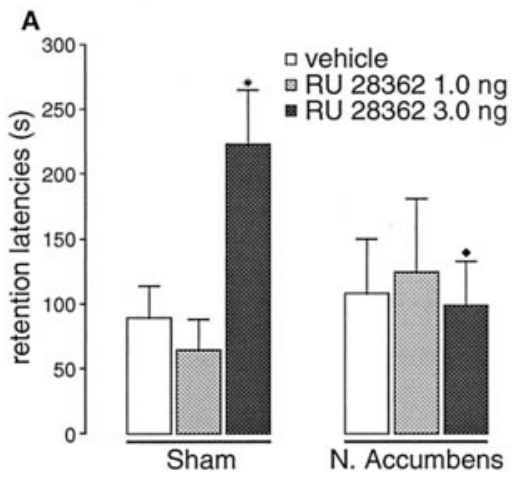

Figure 5. Step-through latencies (mean \pm SEM) for the 48 hr retention test of rats with lesions of either the nucleus accumbens $(A)$ or the stria terminalis $(B)$ given microinfusions of vehicle or the specific glucocorticoid receptor agonist RU 28362 (1.0 or $3.0 \mathrm{ng}$ in $0.5 \mu \mathrm{l}$ ) into the dorsal hippocampus immediately after inhibitory avoidance training. $* p<0.05$ compared with the corresponding vehicle group; $p<0.05$ compared with the corresponding shamlesion group ( $n=7-14$ per group). $N$., Nucleus. higher dose of RU 28362 to induce retention enhancement compared with that required in the BLA. However, because the volume infused into the hippocampus was also larger than that infused into the BLA, the final concentrations of the effective drug solutions in both structures were comparable. The effects of glucocorticoid administration on retention performance depend not only on the dose but also, among other factors, on the phases of memory during which they are active (Lupien and McEwen, 1997; de Quervain et al., 1998). In the present experiments, RU 28362 was administered in a single infusion after the training experience and, thus, could not have affected processes influencing acquisition. Likewise, because neither systemic nor intrahippocampal glucocorticoid administration enhances memory when given several hours after training (Flood et al., 1978; Micheau et al., 1985; Sandi and Rose, 1994; Cabib et al., 1996), the retention enhancement seen in the present study was most likely caused selectively by an influence on memory consolidation. Further support for the hypothesis that immediate post-training administration of a GR agonist selectively influences memory consolidation is provided by our finding that systemic administration of glucocorticoids shortly before retention testing impairs retention performance for training in several tasks, including inhibitory avoidance (de Quervain et al., 1998) (B. Roozendaal and J. L. McGaugh, unpublished observation). Lastly, direct glucocorticoid effects on locomotor activity seem not to be mediated by GR activation (Oitzl et al., 1994; Sandi et al., 1996). Thus, it is not likely that the glucocorticoid influence on retention latencies is caused by alteration of locomotor activity.

\section{The BLA as a modulator of hippocampal memory function}

Extensive evidence from our laboratory suggests that the BLA is not a critical long-term information storage site but rather that the BLA regulates memory consolidation processes in other brain regions (McGaugh et al., 1996; McGaugh, 2000). There is accumulating agreement that the BLA is involved in regulating storage of recently acquired information in or involving the hippocampus. Direct post-training BLA activation by pharmacological treatments (including glucocorticoids) can enhance memory in several (hippocampal-dependent) learning tasks (Packard et al., 1994; Roozendaal and McGaugh, 1997b; Hatfield and McGaugh, 1999). This amygdala-induced memory enhancement is blocked in animals in which the hippocampus is inactivated concurrently (Packard and Teather, 1998). Additionally, an intact BLA is necessary for the memory-modulatory effects of both systemic and intrahippocampal glucocorticoid administration (Roozendaal and McGaugh, 1996a, 1997a). BLA lesions also block the impairing effects of adrenalectomy, or of GR antagonist administration into the hippocampus, on memory for water-maze spatial training (Roozendaal et al., 1996; Roozendaal and McGaugh, 1997a). Although the nature of this BLA influence on memory processes involving the hippocampus is not clear, it is known that this enabling influence is not limited to glucocorticoids. BLA inactivation also blocks memory enhancement induced by post-training intrahippocampal glutamate administration in a win-shift version of the radial arm maze (Packard and Chen, 1999).

\section{Role of the nucleus accumbens in BLA-hippocampus interactions}

Several recent studies using either systemic injections of drugs combined with lesions of the NAc or the ST or local drug inf usions into the NAc have implicated the NAc and the ST in the modulation of memory consolidation (Introini-Collison et al., 1991; Lorenzini et al., 1995; Roozendaal and McGaugh, 1996b; Setlow and McGaugh, 1999). The present study evaluated the participation of the NAc and the ST in influencing memory consolidation involving the BLA and the dorsal hippocampus. The finding that NAc and ST lesions block the enhancing effect of intra-BLA infusions of RU 28362 on inhibitory avoidance memory suggests that ST projections, terminating in the NAc, mediate BLA effects of stress hormones and emotional arousal on memory consolidation in other brain regions. This view is supported by previous findings indicating that ST lesions block the memorymodulatory effects of other amygdala manipulations, including electrical and noradrenergic stimulation (Liang and McGaugh, 1983; Introini-Collison et al., 1991). Unequivocal evidence implicating this pathway in memory modulation was provided by the finding that contralateral, unilateral BLA and NAc lesions (thus damaging the BLA-NAc pathway in both hemispheres) block inhibitory avoidance retention enhancement induced by systemic dexamethasone, whereas ipsilateral destruction of these brain regions is ineffective (Setlow et al., 2000). The involvement is not limited to inhibitory avoidance learning because ST lesions also block systemic glucocorticoid effects on memory consolidation on a water-maze spatial task (Roozendaal and McGaugh, 1996b).

Evidence from neurochemical and electrophysiological experiments suggests that the BLA may influence hippocampal activity via direct projections or via the entorhinal cortex (Thomas et al., 1984; Ikegaya et al., 1994, 1995; Packard et al., 1995; Akirav and Richter-Levin, 1999; Pikkarainen et al., 1999; Sharp et al., 1999). However, the BLA is not only engaged in modulating long-term consolidation processes, but it also influences other hippocampaldependent cognitive processes such as acquisition and/or encod- 
ing (Shors and Mathew, 1997; Poremba and Gabriel, 1999; Spanis et al., 1999). Direct BLA-hippocampal connections might be involved in influencing these more short-term cognitive processes. In contrast, the present findings suggest that these direct anatomical pathways may not participate in mediating BLA effects on memory consolidation processes. Perhaps the strongest argument against an involvement of direct BLA-hippocampus connections in mediating BLA influences on memory consolidation is the present finding that ST lesions block the memoryenhancing effects of intrahippocampal glucocorticoid administration. BLA projections to the hippocampus do not run through the ST. These findings suggest that the BLA-NAc projections are critical for regulation of the memory-modulatory influences of glucocorticoids in the hippocampus. The finding that a disruption of the BLA-NAc pathway (at the level of either the BLA, ST, or NAc) blocks the enhancing effects of intrahippocampal GR agonist infusions on memory consolidation suggests that the NAc may be a site of convergence for memory-modulatory information from the BLA and the hippocampus.

Many of the same kinds of learning that involve the hippocampus also involve the NAc, which receives a strong projection from the hippocampus (Kelley and Domesick, 1982; Groenewegen et al., 1987; Seamans and Phillips, 1994; Logan and Grafton, 1995; Setlow, 1997; Westbrook et al., 1997; Goldenberg et al., 1999; Setlow and McGaugh, 1999). However, in contrast to the present findings, lesions of the NAc often impair performance, particularly on hippocampal-dependent tasks. Also, as we noted above, post-training inactivation of the NAc impairs later inhibitory avoidance retention (Lorenzini et al., 1995), providing further evidence of a modulatory role of the NAc in this task. It appears that the NAc is a critical link in the process by which glucocorticoids enhance memory consolidation, and it can be hypothesized that BLA input to the NAc "gates" the influence of hippocampal glucocorticoids on memory consolidation.

Considerable evidence indicates the convergence of BLA and hippocampal information onto single cells in the NAc (DeFrance et al., 1980; Lavoie and Mizumori, 1994; O'Donnell and Grace, 1995; Finch, 1996). Moreover, electrical stimulation of the BLA increases the likelihood that fimbria-fornix stimulation will induce spike activity in the NAc (Mulder et al., 1998), and lesioning of the fimbria-fornix impairs BLA-induced reinforcement of perforant path LTP (Jas et al., 2000). This proposed role of the NAc in integrating BLA- and hippocampal-derived information is not unique for memory modulation. It was proposed originally by Mogenson et al. (1980) to explain limbic influences on locomotor activity, and subsequently several learned and unlearned behaviors were found to use this pathway (Roozendaal and Cools, 1994; Floresco et al., 1997; Everitt et al., 1999). There appear to be differing levels of complexity in BLA-hippocampal-NAc interactions that may be task dependent (see Hiroi and White, 1991). Because the NAc is presumably not a critical locus of storage for memory (Sutherland and Rodriguez, 1989; Haralambous and Westbrook, 1999) and because the projections from the BLA and the hippocampus to the NAc are unidirectional, this information may feed back to cortical areas (including the hippocampus), perhaps via striatopallidothalamocortical loops, to allow for more long-lasting storage (Alexander et al., 1990; De Olmos and Heimer, 1999).

BLA activation may have widespread effects on memory function throughout the brain. The BLA modulates immediate-early gene expression, LTP, and cognitive processes in or involving the caudate-putamen (Packard et al., 1994) and several cortical areas
(Liang et al., 1996; Bermudez-Rattoni et al., 1997; Escobar et al., 1998; Jones et al., 1999; Schoenbaum et al., 1999). It will be of interest to determine whether these effects are also mediated by converging influences involving the NAc.

\section{REFERENCES}

Akirav I, Richter-Levin G (1999) Biphasic modulation of hippocampal plasticity by behavioral stress and basolateral amygdala stimulation in the rat. J Neurosci 19:10530-10535.

Alexander GE, Crutcher MD, DeLong MR (1990) Basal gangliathalamocortical circuits: parallel substrates for motor, oculomotor, "prefrontal" and "limbic" functions. Prog Brain Res 85:119-146.

Bermudez-Rattoni F, Introini-Collison I, Coleman-Mesches K, McGaugh JL (1997) Insular cortex and amygdala lesions induced after aversive training impair retention: effects of degree of training. Neurobiol Learn Mem 67:57-63.

Cabib S, Castellano C, Patacchioli FR, Cigliana G, Angelucci L, PuglisiAllegra S (1996) Opposite strain-dependent effects of post-training corticosterone in a passive avoidance task in mice: role of dopamine. Brain Res 729:110-118.

Cahill L, McGaugh JL (1998) Mechanisms of emotional arousal and lasting declarative memory. Trends Neurosci 21:294-299.

DeFrance JF, Marchand JE, Stanley JC, Sikes RW, Chronister RB (1980) Convergence of excitatory amygdaloid and hippocampal input in the nucleus accumbens septi. Brain Res 185:183-186.

de Kloet ER, Oitzl MS, Joëls M (1999) Stress and cognition: are corticosteroids good or bad guys? Trends Neurosci 22:422-426.

De Olmos JS, Heimer L (1999) The concepts of the ventral striatopallidal system and extended amygdala. Ann NY Acad Sci 877:1-32.

de Quervain DJ-F, Roozendaal B, McGaugh JL (1998) Stress and glucocorticoids impair retrieval of long-term spatial memory. Nature 394:787-790.

Escobar ML, Chao V, Bermudez-Rattoni F (1998) In vivo long-term potentiation in the insular cortex: NMDA receptor dependence. Brain Res 779:314-319.

Everitt BJ, Parkinson JA, Olmstead MC, Arroyo M, Robledo P, Robbins TW (1999) Associative processes in addiction and reward: the role of amygdala-ventral striatal subsystems. Ann NY Acad Sci 877:412-438.

Finch DM (1996) Neurophysiology of converging synaptic inputs from the prefrontal cortex, amygdala, midline thalamus, and hippocampal formation onto single neurons of the caudate/putamen and nucleus accumbens. Hippocampus 6:495-512.

Flood JF, Vidal D, Bennett EL, Orme AE, Vasquez S, Jarvik ME (1978) Memory facilitating and anti-amnestic effects of corticosteroids. Pharmacol Biochem Behav 8:81-87.

Floresco SB, Seamans JK, Phillips AG (1997) Selective roles for hippocampal, prefrontal cortical, and ventral striatal circuits in radial-arm maze tasks with or without a delay. J Neurosci 17:1880-1890.

Gold PE (1986) The use of avoidance training in studies of modulation of memory storage. Behav Neural Biol 46:87-98.

Goldenberg G, Schuri U, Gromminger O, Arnold U (1999) Basal forebrain amnesia: does the nucleus accumbens contribute to human memory? J Neurol Neurosurg Psychiatry 67:163-168.

Groenewegen HJ, Vermeulen-Van der Zee E, te Kortschot A, Witter MP (1987) Organization of the projections from the subiculum to the ventral striatum in the rat: a study using anterograde transport of Phaseolus vulgaris leucoagglutinin. Neuroscience 23:103-120.

Haralambous T, Westbrook RF (1999) An infusion of bupivacaine into the nucleus accumbens disrupts the acquisition but not the expression of contextual fear conditioning. Behav Neurosci 113:925-940.

Hatfield T, McGaugh JL (1999) Norepinephrine infused into the basolateral amygdala enhances spatial water maze memory. Neurobiol Learn Mem 71:232-239.

Hiroi N, White NM (1991) The lateral nucleus of the amygdala mediates expression of the amphetamine-produced conditioned place preference. J Neurosci 11:2107-2116.

Honkaniemi J, Pelto-Huikko M, Rechardt L, Isola J, Lammi A, Fuxe K, Gustafsson JA, Wikström A-C, Hökfelt T (1992) Colocalization of peptide and glucocorticoid receptor immunoreactivities in rat central amygdaloid nucleus. Neuroendocrinology 55:451-459.

Ikegaya Y, Saito H, Abe K (1994) Attenuated hippocampal long-term potentiation in basolateral amygdala-lesioned rats. Brain Res 656:157-164.

Ikegaya Y, Saito H, Abe K (1995) High-frequency stimulation of the basolateral amygdala facilitates the induction of long-term potentiation in the dentate gyrus in vivo. Neurosci Res 22:203-207.

Introini-Collison IB, Miyazaki B, McGaugh JL (1991) Involvement of the amygdala in the memory-enhancing effects of clenbuterol. Psychopharmacology (Berl) 104:541-544.

Jas J, Almaguer W, Frey JU, Bergado J (2000) Lesioning the fimbriafornix impairs basolateral amygdala induced reinforcement of LTP in the dentate gyrus. Brain Res 861:186-189.

Jones MW, French PJ, Bliss TVO, Rosenblum K (1999) Molecular 
mechanisms of long-term potentiation in the insular cortex in vivo. J Neurosci 19:RC36.

Kelley AE, Domesick VB (1982) The distribution of the projection from the hippocampal formation to the nucleus accumbens in the rat: an anterograde- and retrograde-horseradish peroxidase study. Neuroscience 7:2321-2335.

Kelley AE, Domesick VB, Nauta WJH (1982) The amygdalostriatal projection in the rat: an anatomical study by anterograde and retrograde tracing methods. Neuroscience 7:615-630.

Kovacs GL, Telegdy G, Lissak K (1977) Dose-dependent action of corticosteroids on brain serotonin content and passive avoidance behavior. Horm Behav 8:155-165.

Lavoie AM, Mizumori SJY (1994) Spatial, movement- and rewardsensitive discharge by medial ventral striatum neurons of rats. Brain Res 638:157-168.

Liang KC (2001) Epinephrine modulation of memory: amygdala activation and regulation of long-term memory storage. In: Four decades of memory: a festschrift honoring James L. McGaugh (Gold PE, Greenough WT, eds), in press. Washington, DC: American Psychological Association.

Liang KC, McGaugh JL (1983) Lesions of the stria terminalis attenuate the amnestic effect of amygdaloid stimulation on avoidance responses. Brain Res 274:309-318.

Liang KC, McGaugh JL, Yao H-Y (1990) Involvement of amygdala pathways in the influence of post-training intra-amygdala norepinephrine and peripheral epinephrine on memory storage. Brain Res 508:225-233.

Liang KC, Hu SJ, Chang SC (1996) Formation and retrieval of inhibitory avoidance memory: differential role of glutamate receptors in the amygdala and medial prefrontal cortex. Chin J Physiol 39:155-166.

Logan CG, Grafton ST (1995) Functional anatomy of human eyeblink conditioning determined with regional cerebral glucose metabolism. Proc Natl Acad Sci USA 92:7500-7504.

Lorenzini CA, Baldi E, Bucherelli C, Tassoni G (1995) Time-dependent deficits in rat's memory consolidation induced by tetrodotoxin injections into the caudate-putamen, nucleus accumbens, and globus pallidus. Neurobiol Learn Mem 63:87-93.

Lupien SJ, McEwen BS (1997) The acute effects of corticosteroids on cognition: integration of animal and human studies. Brain Res Rev $24: 1-27$.

McGaugh JL (2000) Memory: a century of consolidation. Science 287:248-251.

McGaugh JL, Introini-Collison IB, Nagahara A (1988) Memoryenhancing effects of post-training naloxone: involvement of $\beta$-adrenergic influences in the amygdaloid complex. Brain Res 446:37-49.

McGaugh JL, Cahill L, Roozendaal B (1996) Involvement of the amygdala in memory storage: interaction with other brain systems. Proc Natl Acad Sci USA 93:13508-13514.

Micheau J, Destrade C, Soumireu-Mourat B (1985) Time-dependent effects of post-training intrahippocampal injections of corticosterone on retention of appetitive learning tasks in mice. Eur $\mathrm{J}$ Pharmacol 106:39-46.

Mogenson GJ, Jones DL, Yim CY (1980) From motivation to action: functional interface between the limbic system and the motor system. Prog Neurobiol 14:69-97.

Mulder AB, Hodenpijl MG, Lopes da Silva FH (1998) Electrophysiology of the hippocampal and amygdaloid projections to the nucleus accumbens of the rat: convergence, segregation, and interaction of inputs. J Neurosci 18:5095-5102.

O’Donnell P, Grace AA (1995) Synaptic interactions among excitatory afferents to nucleus accumbens neurons: hippocampal gating of prefrontal cortical input. J Neurosci 15:3622-3639.

Oitzl MS, Fluttert M, de Kloet ER (1994) The effect of corticosterone on reactivity to spatial novelty is mediated by central mineralocorticoid receptors. Eur J Neurosci 6:1072-1079.

Packard MG, Chen S (1999) The basolateral amygdala is a co-factor in memory enhancement produced by intra-hippocampal glutamate injections. Psychobiology 27:377-385.

Packard MG, Teather L (1998) Amygdala modulation of multiple memory systems, hippocampus and caudate-putamen. Neurobiol Learn Mem 69:163-203.

Packard MG, Cahill L, McGaugh JL (1994) Amygdala modulation of hippocampal-dependent and caudate nucleus-dependent memory processes. Proc Natl Acad Sci USA 91:8477-8481.

Packard MG, Williams CL, Cahill L, McGaugh JL (1995) The anatomy of a memory modulatory system: from periphery to brain. In: Neurobehavioral plasticity, learning, development and response to brain insults (Spear N, Spear L, Woodruff M, eds), pp 149-184. Hillsdale, NJ: Erlbaum.

Parent MB, McGaugh JL (1994) Posttraining infusion of lidocaine into the amygdala basolateral complex impairs retention of inhibitory avoidance training. Brain Res 661:97-103.

Paxinos G, Watson C (1997) The rat brain in stereotaxic coordinates, 3rd edition. San Diego: Academic.

Pellegrino LJ, Pellegrino AS, Cushman AJ (1979) A stereotaxic atlas of the rat brain. New York: Academic.
Pikkarainen M, Ronkko S, Savander V, Insausti R, Pitkanen A (1999) Projections from the lateral, basal, and accessory basal nuclei of the amygdala to the hippocampal formation in rat. J Comp Neurol 403:229-260

Poremba A, Gabriel M (1999) Amygdala neurons mediate acquisition but not maintenance of instrumental avoidance behavior in rabbits. J Neurosci 19:9635-9641.

Reul JMHM, de Kloet ER (1985) Two receptor systems for corticosterone in the rat brain: microdistribution and differential occupation. Endocrinology 117:2505-2512.

Roozendaal B (2000) Glucocorticoids and the regulation of memory consolidation. Psychoneuroendocrinology 25:213-238.

Roozendaal B, Cools AR (1994) Influence of the noradrenergic state of the nucleus accumbens in basolateral amygdala mediated changes in neophobia. Behav Neurosci 108:1107-1118.

Roozendaal B, McGaugh JL (1996a) Amygdaloid nuclei lesions differentially affect glucocorticoid-induced memory enhancement in an inhibitory avoidance task. Neurobiol Learn Mem 65:1-8.

Roozendaal B, McGaugh JL (1996b) The memory-modulatory effects of glucocorticoids depend on an intact stria terminalis. Brain Res 709:243-250.

Roozendaal B, McGaugh JL (1997a) Basolateral amygdala lesions block the memory-enhancing effect of glucocorticoid administration in the dorsal hippocampus of rats. Eur J Neurosci 9:76-83.

Roozendaal B, McGaugh JL (1997b) Glucocorticoid receptor agonist and antagonist administration into the basolateral but not central amygdala modulates memory storage. Neurobiol Learn Mem 67:176-179.

Roozendaal B, Portillo-Marquez G, McGaugh JL (1996) Basolateral amygdala lesions block glucocorticoid-induced modulation of memory for spatial learning. Behav Neurosci 110:1074-1083.

Roozendaal B, Nguyen BT, Power AE, McGaugh JL (1999) Basolateral amygdala noradrenergic influence enables enhancement of memory consolidation induced by hippocampal glucocorticoid receptor activation. Proc Natl Acad Sci USA 96:11642-11647.

Sandi C, Rose S (1994) Corticosterone enhances long-term retention in one day-old chicks trained in a weak passive avoidance learning paradigm. Brain Res 647:106-112.

Sandi C, Venero C, Guaza C (1996) Novelty-related rapid locomotor effects of corticosterone in rats. Eur J Neurosci 8:794-800.

Schoenbaum G, Chiba AA, Gallagher M (1999) Neural encoding in orbitofrontal cortex and basolateral amygdala during olfactory discrimination learning. J Neurosci 19:1876-1884.

Seamans JK, Phillips AG (1994) Selective memory impairments produced by transient lidocaine-induced lesions of the nucleus accumbens in rats. Behav Neurosci 108:456-468.

Setlow B (1997) The nucleus accumbens and learning and memory. J Neurosci Res 49:515-521.

Setlow B, McGaugh JL (1999) Differential effects of immediate posttraining sulpiride infusions into the nucleus accumbens core and shell on retention in the Morris water maze. Psychobiology 27:248-255.

Setlow B, Roozendaal B, McGaugh JL (2000) Involvement of a basolateral amygdala complex-nucleus accumbens pathway in glucocorticoidinduced modulation of memory consolidation. Eur J Neurosci $12: 367-375$

Sharp PE, Kim JJ, Lee HJ (1999) Amygdalar lesions block stressinduced impairment of long-term potentiation in rat hippocampus. Soc Neurosci Abstr 15:1620.

Shors TJ, Mathew PR (1997) NMDA receptor antagonism in the lateral/ basolateral but not central nucleus of the amygdala prevents the induction of facilitated learning in response to stress. Learn Mem 5:220-230.

Spanis CW, Bianchin MM, Izquierdo I, McGaugh JL (1999) Excitotoxic basolateral amygdala lesions potentiate the memory impairment effect of muscimol injected into the medial septal area. Brain Res 816:329-336.

Sutherland RJ, Rodriguez AJ (1989) The role of the fornix/fimbria and some related subcortical structures in place learning and memory. Behav Brain Res 32:265-277.

Taubenfeld S, Wiig K, Bear M, Alberini C (1999) A molecular correlate of memory and amnesia in the hippocampus. Nat Neurosci 2:309-310.

Teutsch G, Costerousse G, Deraedt R, Benzoni J, Fortin M, Philibert D (1981) 17Alpha-alkynyl-11beta,17-dihydroxyandrostane derivatives: a new class of potent glucocorticoids. Steroids 38:651-665.

Thomas SR, Assaf SY, Iversen SD (1984) Amygdaloid complex modulates neurotransmission from the entorhinal cortex to the dentate gyrus of the rat. Brain Res 307:363-365.

Vazdarjanova A, McGaugh JL (1998) Basolateral amygdala is not critical for cognitive memory of contextual fear conditioning. Proc Natl Acad Sci USA 95:15003-15007.

Westbrook RF, Good AJ, Kiernan MJ (1997) Microinjection of morphine into the nucleus accumbens impairs contextual learning in rats. Behav Neurosci 111:996-1013.

Wright CI, Beijer AVJ, Groenewegen HJ (1996) Basal amygdaloid afferents to the rat nucleus accumbens are compartmentally organized. J Neurosci 16:1877-1893. 